\title{
Corrosion Inhibition of Henna Extract on Carbon Steel with Hybrid Coating TMSM-PMMA in HCL Solution
}

\author{
Zahra Khoshkhou, Maryam Torkghashghaei*, Amin Rabiei Baboukani \\ Advanced Materials Research Center, Materials Engineering Department, Najafabad Branch, Islamic Azad University, Najafabad, Iran \\ Email: *Maryam.t.ghashghaei@gmail.com
}

How to cite this paper: Khoshkhou, Z., Torkghashghaei, M. and Baboukani, A.R. (2018) Corrosion Inhibition of Henna Extract on Carbon Steel with Hybrid Coating TMSM-PMMA in HCL Solution. Open Journal of Synthesis Theory and Applications, 7, 1-16.

https://doi.org/10.4236/ojsta.2018.71001

Received: January 10, 2018

Accepted: January 28, 2018

Published: January 31, 2018

Copyright $\odot 2018$ by authors and Scientific Research Publishing Inc. This work is licensed under the Creative Commons Attribution International License (CC BY 4.0).

http://creativecommons.org/licenses/by/4.0/

(c) (i) Open Access

\begin{abstract}
Green inhibitors are promising alternatives to toxic corrosion inhibitors as they are environmentally safe substances, ecologically acceptable and renewable. In this research, the effect of green henna as an inhibitor existing in the coating of TMSM-PMMA and its electrochemical study were analyzed. The coating was produced by "sol-gel" method in order to protect the corrosion of low-carbon steel. TMSM hybrid cell was synthesized by hydrolysis and condensation, Metaacryloxypropyltrimethoxysilane and Tetraetylorthosilicate with 1:1 molar ratio and PMMA hybrid cell was produced by Methylmetaacrylate polymerization. Finally two cells were mixed in 1:1 weight ratio. The carbon steel substrates were prepared by dip coating method. SEM technique was applied for the microstructure evaluation of thin layers including different concentrations of henna extract. Adhesion of coating was analyzed by "Pull off" test. Additionally, the experimental results obtained in different concentrations of henna extract using electrochemical methods such as tafel polarization, electrochemical impedance spectroscopy indicating that coating with the concentration of $3 \%$ inhibitor had a high level of inhibition efficiency in 0.1 M HCL. The results of polarization tests signified that henna extract acts as a mixed inhibitor.
\end{abstract}

\section{Keywords}

Carbon Steel, Corrosion Inhibition, Henna Extract, Polarization, EIS

\section{Introduction}

Carbon steels play an important role in industrial environment because of their good mechanical and physical properties as well as low cost [1]. However, they 
are susceptible to get attacked while being applied in corrosive solutions including aggressive compounds like HCL. Corrosion is a devastative phenomenon occurring due to the chemical or electrochemical reaction of substance with its surrounded environment. There exists a wide variety of methods by which corrosion can be prevented by the means of inhibitors and coatings. Coatings prevent exchanging electrons in electrochemical reaction. Because of this mechanism, a protective layer is formed between the substrate and the aggressive medium [2]. Compounds which are practically beneficial for the protection of metals are extremely toxic and can result in cancer [3]. One of the appropriate ways for the surface protection of some materials could be by the use of hybrid organic-inorganic sol-gels which are considered as suitable option for this purpose [4]. Sol-gel coatings have high quality of flexibility, hydrophobic properties, anti-corrosion, transparency and suitable adhesion to the substrate. The combination of polysiloxan with siloxan and polymer constitute a hybrid coating contributing to the appropriate control of corrosion. The main role of these hybrid materials is production of a very thin layer having good yields and it does not permit oxygen to diffuse to the surface of the metal [5] [6] [7] [8]. When coverage of the coating has a defect, its corrosion protection properties will be boosted by the presence of active corrosion inhibitors [9] [10] [11] [12].

When organic inhibitor is added into hybrid coating, it becomes compatible with the present coating contributing to cross linking and film formation. The mechanism of inhibition is through inhibitor incorporation in the film, moving and precipitating. This procedure results in the constitution of passivating effect while a defect has emanated. Researchers have focused on natural products, for most of the synthetic organic inhibitors have inevitable hazardous effects. One of the organic compounds named henna is known as corrosion inhibitor having some merits such as profusion and being eco-friendly, and nontoxic [13]. In particular, hybrid coatings produced by sol-gel method have both inorganic and organic properties. It is possible to acquire an extensive diversity of hybrid sol-gel-derived materials, since an array of precursors for constituting inorganic component such as metal alkoxides, organo (alkoxy) silanes, and nanoparticles is available [14]. On top of that, they are highly compatible with polymerizable groups. The main usage of these types of materials is as coating. In addition, they have been used as bulk materials. Hybrid coatings are made up of a dual polymer network, in which inorganic parts are bound to polymer chains [15].

Polymeric mixture forming from the existing of PMMA results in improving the properties of organic-inorganic hybrid coating. The classification of these materials is based on their chemical bond characteristics, thus they are classified into two general categories. Category I is in relation with hybrid films, in which inorganic fragments and organic polymers in the hybrid coating form weak bonds of the types Van der Waals, hydrogen, or ionic interaction, whereas Category II has strong bonds such as covalent or ionic covalent chemical ones [16] [17] [18] [19].

By the suitable selection of inorganic and organic parts and their composi- 
tions, fresh and versatile hybrid materials can be acquired [16]. Providing the link between the organic and inorganic parts is a main step. When the bonds between these two parts are covalent, hybrids properties will be enhanced. For example, the connection between organic and inorganic phases like trialkoxysilane and vinylic ligands constitutes an appropriate bond [20] [21]. One type of trialkoxysilane is 3 methacryloxypropyltrimethoxysilane (TMSM, also known as MPTS) which has photo-sensitivity to UV radiation, thus it is used in optical equipment [22] [23] [24]. By the formation of a polymer from TMSM and PMMA creating by UV radiation or by heat treatments, the refractive characteristic will rise [25].

In the present research, an organic-inorganic coating was prepared from the processes namely; polymerization, hydrolysis and condensation reactions of TMSM-PMMA and henna extract. Carbon steel ST37 was applied as the substrate. The hybrid film structure, with the addition of inhibitors into its network, was studied using SEM. The efficiency of protective coatings in the presence and absence of inhibitors was evaluated using potentiodynamic polarization and electrochemical impedance spectroscopy (EIS).

\section{Experimental}

\subsection{Specimen Preparation}

Carbon steel (ST37) having nominal composition of $0.179 \% \mathrm{C}, 0.165 \% \mathrm{Si}$, $0.439 \% \mathrm{Mn}, 0.203 \% \mathrm{Cu}, 0.034 \% \mathrm{~S}$ and Fe balance is used. It is cut into $2 \times 2 \times 0.2$ $\mathrm{cm}$ dimensions used for electrochemical characterization. Specimens were mechanically abraded with $100,200,400,600,800,1000$ grades of emery papers, then degreased by acetone and hand washed with distilled water.

\subsection{Solution Preparation}

Corrosion electrolyte was obtained by mixing $4.2 \mathrm{ml}$ of HCL $37 \%$ with $500 \mathrm{ml}$ distilled water in order to prepare $0.1 \mathrm{M}$ HCL.

\subsection{Inhibitor Preparation}

The hybrid layers were prepared by a sol-gel method constituted by the following components: TMSM $\left(\mathrm{C}_{10} \mathrm{H}_{20} \mathrm{O}_{5} \mathrm{Si}\right.$, Merck $)$ and TEOS $\left(\mathrm{C}_{8} \mathrm{H}_{20} \mathrm{O}_{4} \mathrm{Si}\right.$, Merck) with the addition of MMA $\left(\mathrm{C}_{5} \mathrm{H}_{8} \mathrm{O}_{2}\right.$, Merck) and the thermal initiator benzoyl peroxide (BPO- $\mathrm{C}_{14} \mathrm{H}_{10} \mathrm{O}_{4}$, Reagent). For the preparation of the hybrid organic-inorganic films a sol-gel method was employed. The formation of these hybrid coatings includes the chemical reactions such as hydrolysis of the alkoxide precursors, condensation leading to the formation of the inorganic phase (polysiloxane), and polymerization of the methylmethacrylate material. Figure 1 depicts the structures of the reagents used in the synthesis of the TMSM-PMMA coating.

First Step: 1.24 gr TMSM and $0.024 \mathrm{gr}$ BPO were mixed for $15 \mathrm{~min}$ at room temperature. Then $1.04 \mathrm{gr}$ TEOS was added slightly and mixed for approximately $15 \mathrm{~min}$. The next stage was adding $5 \mathrm{ml} \mathrm{ETOH}$ and $100 \mu \mathrm{HCL}(0.01 \mathrm{M})$ 
<smiles>C=C(C)C(=O)OC</smiles>

MMA

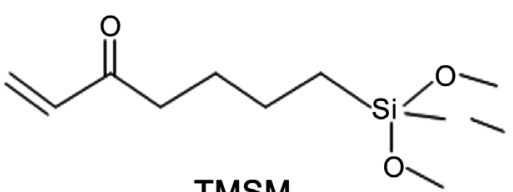

TMSM

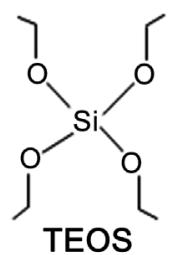

Figure 1. Molecular structure of the component of TMSM-PMMA coating [15].

and finally the whole mixture was mixed for about 1 hour at room temperature. The solution of henna extract with the concentration of $1 \%, 3 \%, 6 \%, 9 \%$ was added to the solution of this step.

Second Step: 5 gr MMA and 0.12 BPO were mixed at room temperature for $30 \mathrm{~min}$.

Third Step: For preparation of the sol-gel TMSM-PMMA $0.5 \mathrm{gr}$ of the solution in the second step was mixed by the whole solution of the first step.

All the blending stages must be in the closed beaker. The specimens were immersed in the hybrid sol for 45 seconds, and then oven-dried for approximately $30 \mathrm{~min}$ at $75^{\circ} \mathrm{C}$. In the sol-gel method the inorganic phase was prepared by mixing TMSM and TEOS at $60^{\circ} \mathrm{C}$ for 1 hour.

\subsection{Electrochemical Measurements}

Electrochemical experiments were carried out in a conventional three-electrode cell with a graphite as a counter electrode (CE), prepared specimens (ST37) as the working electrodes (WE) and a standard calomel electrode (SCE) was used as the reference electrode. Electrochemical measurements were organized at room temperature in HCL solution $(0.1 \mathrm{M})$ using an electrochemical unit (model PARSTAT 2273). The potentiodynamic polarization curves were conducted from the -250 to $+250 \mathrm{mv}$ vs. OCP, at a sweep rate of $0.5 \mathrm{mV} \cdot \mathrm{s}^{-1}$. Electrochemical impedance spectroscopy (EIS) was performed over a frequency range of $100 \mathrm{kHz}$ - $10 \mathrm{MHz}$ and peak-to-peak ac amplitude of $10 \mathrm{~A} \cdot \mathrm{Cm} \cdot \mathrm{V}$. The condition of this test was the immersion of the specimens in $0.1 \mathrm{M} \mathrm{HCL}$ after the time of $0 \mathrm{~h}, 24$ $\mathrm{h}, 72 \mathrm{~h}$ and $168 \mathrm{~h}$.

\section{Results and Discussion}

\subsection{Electrochemical Characterization}

Potentiodynamic polarization measurements of hybrid coating of TMSM-PMMA in the $0.1 \mathrm{M} \mathrm{HCL}$ solution were carried out and the results were compared with the polarization results of the condition in which henna extract of the concentrations 1\%, 3\%, 6\%, 9\% were added to the hybrid coating (Figure 2 ). The inhibition efficiency (IE\%) was computed according to the Equation (1) $[26]:$

$$
I E \%=\left(\left(I_{0}-I\right) / I_{0}\right) \times 100
$$

where, $I_{0}$ is the corrosion current density of hybrid coating and $I$ is the corrosion 


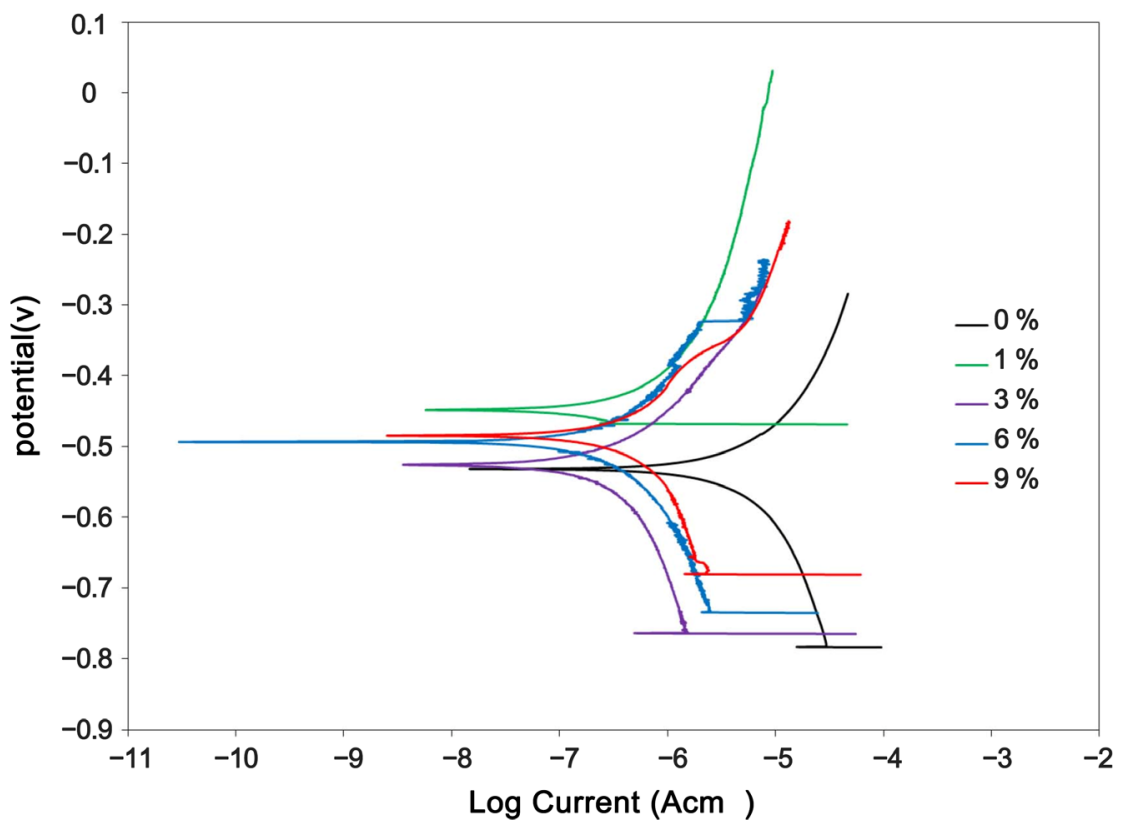

Figure 2. Potentiodynamic polarization curves for hybrid coatings in the HCL $0.1 \mathrm{M}$ with various henna extract concentrations and comparison with the bare metal.

current density of the mentioned coating in which different concentrations of the inhibitor are employed. The rate of corrosion was calculated based on the Equation (2) [26]:

$$
\operatorname{mpy}=\left(0.129 \cdot a \cdot I_{\text {corr }}\right) / n \cdot \mathrm{D}
$$

where $I_{\text {corr }}$ is the corrosion current density in $\mu \mathrm{A} / \mathrm{cm}^{2}$, $a$ is atomic weight of metal in gram, $n$ is the number of lost electron and $\mathrm{D}$ is the density of metal in $\mathrm{gr} / \mathrm{cm}^{3}$. Various parameters like current density $\left(I_{\text {corr }}\right)$, corrosion potential $\left(E_{\text {corr }}\right)$ as well as cathodic and anodic tafel slope $\left(\beta_{\mathrm{c}}\right.$ and $\left.\beta_{\mathrm{a}}\right)$ were assessed from the tafel polarization curves and with the parameters computed from the Equations (1) and (2) all were recorded in Table 1.

According to Table 1 and due to the fact that adding henna extract as an inhibitor in the PMMA (second step of coating preparation) had low efficiency in comparison with the time that it had been added to the TMSM (first step of coating preparation), henna extract was added to the TMSM for all the electrochemical tests. The results of the polarization measurements are given in Table 2.

If the difference in the value of $E_{\text {corr }}\left(\Delta E=E_{\text {corr without inhibitor }}-E_{\text {corr with inhibitor }}\right)$ is higher than $85 \mathrm{mV}$, the inhibitor can be categorized as cathodic or anodic inhibitor. Moreover, if the difference in value of $E_{\text {corr }}$ is lower than $85 \mathrm{mV}$, the inhibitor can be classified as a mixed inhibitor [26] [27] [28]. When an inhibitor is used, a noticeable shift takes place in the cathodic part of tafel curve, while a change in the anodic part is slight. Consequently, henna extract as an inhibitor could be categorized as a mixed-type kind which has a dominant effect in the cathodic part of the polarization curve. Thus, in this study henna extract has acted as a mixed inhibitor. 
Table 1. Kinetic parameters of tafel polarization for carbon steel specimen by adding henna extract to PMMA in TMSM-PMMA coating.

\begin{tabular}{ccccccc}
\hline Medium (w) \% & $-E_{\text {corr }}(\mathrm{mv})^{\mathrm{a}}$ & $I_{\text {corr }}\left(\mu \mathrm{A} / \mathrm{cm}^{2}\right)^{\mathrm{b}}$ & $\beta_{\mathrm{c}}(\mathrm{mV})^{\mathrm{c}}$ & $\beta_{\mathrm{a}}(\mathrm{mV})^{\mathrm{d}}$ & $\% \mathrm{PE}^{\mathrm{e}}$ & $\mathrm{MPY}^{\mathrm{f}}$ \\
\hline No inhibitor & 532 & 4.11 & 583.69 & 348.23 & - & 1.90 \\
$1 \%$ henna extract & 551 & 1.75 & 723.06 & 103.09 & 57.03 & 0.81 \\
\hline
\end{tabular}

${ }^{\mathrm{a} C}$ Corrosion Potential, ${ }^{\mathrm{b}}$ Corrosion Current, 'Cathodictafel slope, ${ }^{\mathrm{d}}$ Anodic tafel slope, ${ }^{\mathrm{e}}$ Protection Efficiency, ${ }^{\mathrm{f}}$ Corrosion Rate.

Table 2. Kinetic parameters of hybrid sol-gel thin films and their comparison with the bare metal in the $0.1 \mathrm{M} \mathrm{HCL}$.

\begin{tabular}{ccccccc}
\hline Medium (w) \% & $-E_{\text {corr }}(\mathrm{mv})$ & $\begin{array}{c}I_{\text {corr }} \\
\left(\mu \mathrm{A} / \mathrm{cm}^{2}\right)\end{array}$ & $\begin{array}{c}\beta_{\mathrm{c}} \\
\mathrm{mV}\end{array}$ & $\begin{array}{c}\beta_{\mathrm{a}} \\
\mathrm{mV}\end{array}$ & $\%$ PE & MPY \\
\hline Bare Metal & 581 & 40.8 & 251.39 & 237.1 & - & 18.89 \\
No inhibitor & 532 & 4.11 & 583.69 & 348.23 & - & 1.90 \\
$1 \%$ henna extract & 448 & 0.25 & 185.21 & 270.42 & 94 & 0.12 \\
3\% henna extract & 523 & 0.059 & 134.06 & 91.13 & 95.6 & 0.02 \\
$6 \%$ henna extract & 494 & 0.17 & 270.1 & 241.35 & 95 & 0.07 \\
$9 \%$ henna extract & 485 & 0.52 & 814.77 & 360.14 & 88.8 & 0.24 \\
\hline
\end{tabular}

The $\beta_{\mathrm{a}}$ and $\beta_{\mathrm{c}}$ values decreased when the concentration of henna extract increased from $1 \%$ to $3 \%$. However, adding the concentration of $6 \%$ and $9 \%$ increased the values of $\beta_{\mathrm{c}}$ and $\beta_{\mathrm{a}}$. This happened because the layer formed was broken so fast [29] [30].

By the use of corrosion current density, the mechanism of corrosion reactions could be assessed. In this study, the bare carbon steel specimen had a higher corrosion rate in comparison with the coated system. By applying TMSM-PMMA hybrid coating, a dramatic decline in the current density was noticed. The higher concentration of henna, the more reduction in anodic current densities. The results showed that the coating with $3 \%$ inhibitor had the lowest anodic current density [31]. This depicts the lower corrosion rate of the coated systems, which means that the substrate had been protected by the hybrid coating. The current density was to be lower when the addition of henna extract acted as an inhibitor. In the absence of inhibitor, the value of the current density was $4.11 \mu \mathrm{A} / \mathrm{cm}^{2}$.

By adding inhibitor, the current density became lower. This occurred when henna extract $1 \%$ was added where the value of current density reached 0.25 $\mu \mathrm{A} / \mathrm{cm}^{2}$. The current density became lower and reaching $0.059 \mu \mathrm{A} / \mathrm{cm}^{2}$ with the addition of 3\% henna extract. The phenomenon occurred because of the process of adsorption on metal surfaces [32]. The value of the current density affected the value of the corrosion rate. In the absence of inhibitor the rate of corrosion was 1.90 MPY, while this value decreased to $0.02 \mathrm{MPY}$ with the addition of $3 \%$ henna extract inhibitor to the hybrid coating. When henna extract added to the amount of $6 \%$ and $9 \%$ in the coating system, the corrosion rate rose owing to 
breaking the layer formed on the metal. Hence, the maximum inhibition efficiency was achieved for TMSM-PMMA coating with $3 \%$ henna extract.

Electrochemical impedance was applied for the corrosion assessment over longer times cales. Typical Nyquist i.e. impedance for hybrid coatings of TMSM-PMMA with $3 \%$ henna extract after $0 \mathrm{~h}, 24 \mathrm{~h}, 72 \mathrm{~h}$ and $168 \mathrm{~h}$ immersion in the 0.1 MHCL was compared with coatings of TMSM-PMMA employed on the bare metal, and the results are shown in Figure 3 and Figure 4, respectively. $0 \mathrm{~h}$ is the initial time when the specimens were exposed to HCL $0.1 \mathrm{M}$ solutions.

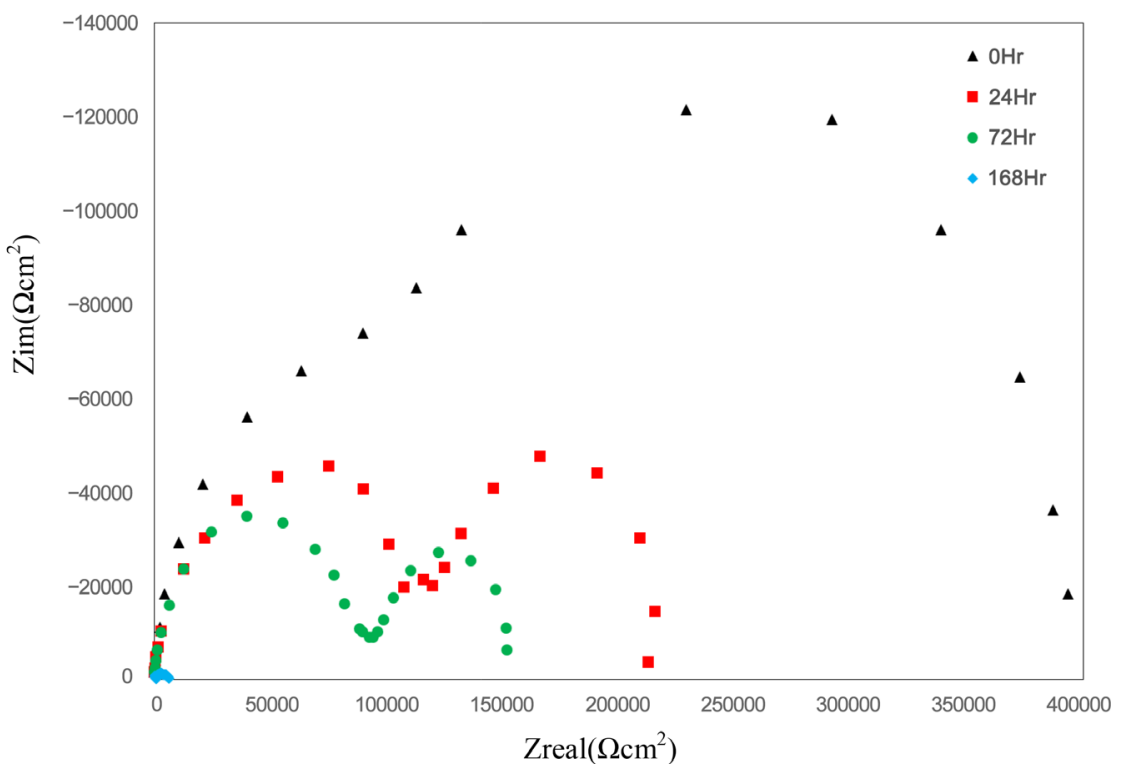

Figure 3. Nyquist plot of hybrid coating of TMSM-PMMA without henna extract after soaking in HCL $0.1 \mathrm{M}$ solution for $0 \mathrm{~h}, 24 \mathrm{~h}, 72 \mathrm{~h}$ and $168 \mathrm{~h}$.

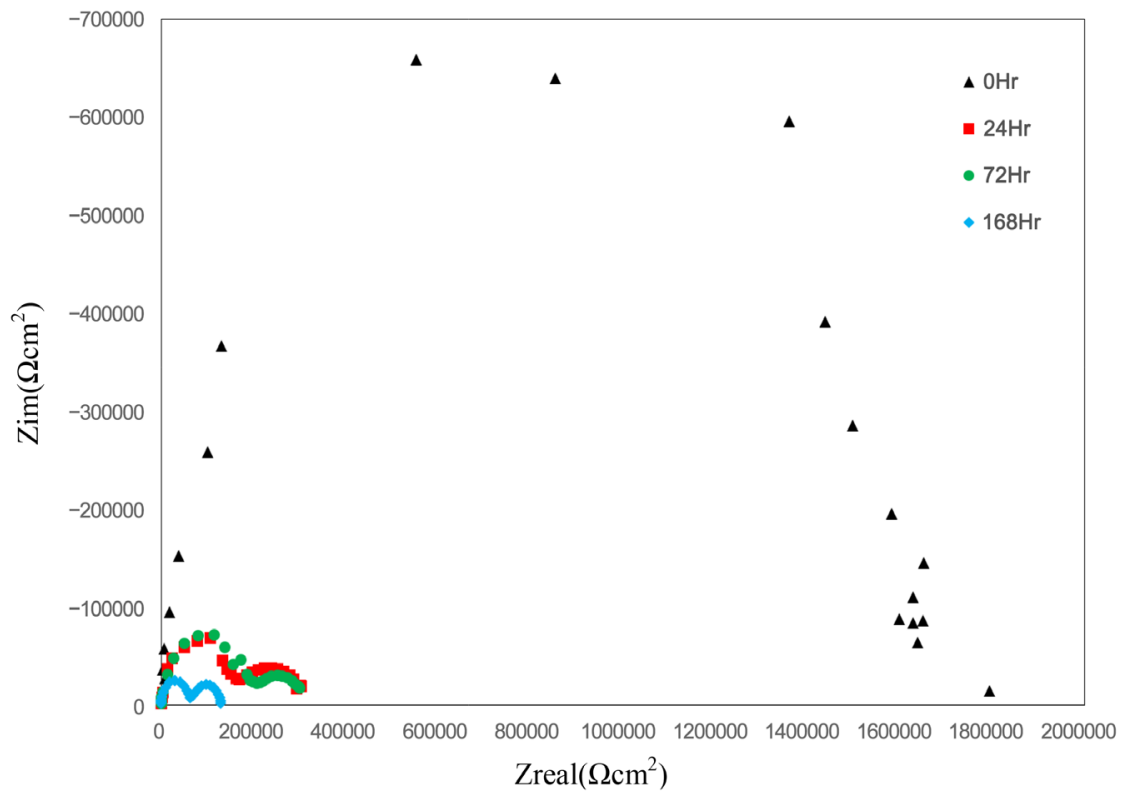

Figure 4. Nyquist plot of hybrid coating of TMSM-PMMA with 3\% henna extract after soaking in HCL $0.1 \mathrm{M}$ solution for $0 \mathrm{~h}, 24 \mathrm{~h}, 72 \mathrm{~h}$ and $168 \mathrm{~h}$. 
In order to represent the response of the electrochemical behavior to EIS tests, an equivalent circuit shown in Figure 5 is the best option. The components of the equivalent circuit are solution resistance $R_{\mathrm{s}}$, capacitance $C_{\mathrm{dl}}$ and polarization resistance $R_{\mathrm{p}}$ for defects in the coatings, and a capacitance $C_{\text {coat }}$ and $R_{\text {coat }}$ for the remainder of the coating layer regarded as intact (non-defective) [33] [34] [35]. The inhibition efficiency of TMSM-PMMA thin film without and with optimum henna extract content after $0 \mathrm{~h}, 24 \mathrm{~h}, 72 \mathrm{~h}$ and $168 \mathrm{~h}$ immersion in HCL $0.1 \mathrm{M}$ solution was assessed by $R_{\mathrm{p}}$ and $C_{\mathrm{dl}}$ values in the impedance test. Values are depicted in Table 3, respectively.

The double layer capacitance $\left(C_{\mathrm{dl}}\right)$ was computed based on the Equation (3) [36]:

$$
C_{\mathrm{dl}}=1 /(\mathrm{RP} 2 \Pi \mathrm{F} \max )
$$

where $C_{\mathrm{dl}}, R_{\mathrm{p}}$ and $F_{\max }$ are double layer capacity, polarization resistance and frequency maximum, respectively. The value of inhibition efficiency of henna extract (IE\%) was according to the Equation (4) [26]:

$$
I E \%=\left(R_{c t}-R_{c t}^{\circ}\right) / R_{c t} \times 100
$$

$R_{c t}$ is the polarization resistance of the hybrid coating while it includes henna as an inhibitor and $R_{c t}^{\circ}$ is the mentioned parameter in the absence of henna extract.

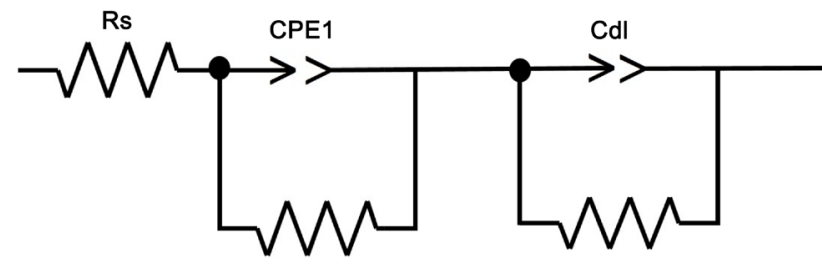

$$
\mathbf{R}_{\mathbf{f}} \quad \mathbf{R}_{\mathrm{ct}}
$$

Figure 5. Equivalent circuits for hybrid coating in the absence and presence of $3 \%$ henna extract.

\begin{tabular}{|c|c|c|c|c|c|c|c|c|c|}
\hline $\begin{array}{l}\text { Medium } \\
\text { (w) } \%\end{array}$ & $\begin{array}{l}\text { Immersion } \\
\text { Time (h) }\end{array}$ & $\begin{array}{c}R_{S} \\
\left(\Omega \cdot \mathrm{cm}^{2}\right)\end{array}$ & $\begin{array}{l}\text { CPE1-T } \\
\left(\mu \mathrm{F} \cdot \mathrm{cm}^{-2}\right)\end{array}$ & CPE1-P & $\begin{array}{c}R_{f} \\
\left(\Omega \cdot \mathrm{cm}^{2}\right)\end{array}$ & $\begin{array}{c}C_{\mathrm{dl}}-\mathrm{T} \\
\left(\mu \mathrm{F} \cdot \mathrm{cm}^{-2}\right)\end{array}$ & $C_{\mathrm{dl}}-\mathrm{p}$ & $\begin{array}{c}R_{C T} \\
\left(\Omega \cdot \mathrm{cm}^{2}\right)\end{array}$ & PE \% \\
\hline \multirow[t]{4}{*}{$\begin{array}{c}\text { No } \\
\text { inhibitor }\end{array}$} & $\begin{array}{c}0 \text { (Initial } \\
\text { time) }\end{array}$ & 4000 & 0.00421 & 0.977 & 90,525 & 63 & 0.88223 & 400,000 & - \\
\hline & 24 & 4000 & 0.013724 & 0.84566 & 113,080 & 2.7438 & 0.90365 & 210,000 & - \\
\hline & 72 & 4000 & 0.010362 & 0.86707 & 85,894 & 1.7015 & 0.76029 & 150,000 & - \\
\hline & 168 & 4000 & 0.008036 & 0.89578 & 55,399 & 1.0127 & 0.78451 & 8500 & - \\
\hline \multirow[t]{4}{*}{$\begin{array}{c}3 \% \text { henna } \\
\text { extract }\end{array}$} & $\begin{array}{c}0 \text { (Initial } \\
\text { time) }\end{array}$ & 4000 & 0.004017 & 1.939 & 39,950 & 4.0551 & 0.87481 & $1,800,000$ & 77.8 \\
\hline & 24 & 4000 & 0.004465 & 0.93413 & 142,140 & 1.3038 & 0.53422 & 310,000 & 32.2 \\
\hline & 72 & 4000 & 0.006237 & 0.90119 & 166,340 & 0.0428 & 0.47487 & 300,000 & 50 \\
\hline & 168 & 4000 & 0.003267 & 0.96628 & 85,082 & 0.0125 & 0.61918 & 190,000 & 95.5 \\
\hline
\end{tabular}

Table 3. Impedance parameters of hybrid coating in the absence and presence of $3 \%$ henna extract in the HCL $0.1 \mathrm{M}$ solution after immersion of $0 \mathrm{~h}, 24 \mathrm{~h}, 72 \mathrm{~h}$ and $168 \mathrm{~h}$. 
The increase in the diameter of the semicircle $\left(R_{\mathrm{ct}}\right)$ in the case of acid solution in the presence of inhibitor was perceived in Figure 3 and Figure 4, indicating a rise in the corrosion resistance of system. In practical, henna extract as an inhibitor rose the impedance. These observations confirm the results of the polarization measurements and the fact that the inhibitor had an increasing effect on the protection behavior of the hybrid coating.

Organic coatings capacitive reactance and resistance properties can also produce a time constant. Water and ions typically diffuse into an organic coating when a coated metal is submerged in an electrolyte, and change the coating dielectric properties. Water and ions also move inside a coating in response AC polarization. However, water and ion movement through (and in) a coating is restricted by coating morphology, producing a coating or pore resistance. Coating time constants can change with time, as electrolyte concentration in the coating changes. Figure 5 depicts the equivalent circuit for undoped/doped hybrid coating with $3 \%$ henna extract with two time constant. Data listed in Table 3 show that by adding inhibitor to the coating, the values of $R_{\mathrm{ct}}$ rose, while $C_{\mathrm{dl}}$ decreased. If $R_{\mathrm{ct}}$ is large, the corrosion rate of the system will be lowered. Hence, the inhibitor creates a high level of protection. The decrease in $C_{\mathrm{dl}}$ is because of an increase of double layer thickness [37]. Therefore the relationship between $R_{\mathrm{ct}}$ and $C_{\mathrm{dl}}$ is inversely proportional [38]. In view of a decrease in local dielectric constant or rise in the density of electric double layer. The presence of henna extract modified the structure of the electric double layer by adsorption inhibitor molecules at the interface of a metal with a solution. By adding an inhibitor in different concentration, the double layer capacitance decreased based on the EIS analysis. Adsorption inhibitor on the metal surface formed a barrier layer to prevent electron transfer. $C_{\mathrm{dl}}$ minimum value occurred by addition of the $3 \%$ henna extract at 168 hour of immersion in acidic media and its value reached $0.0125 \mu \mathrm{F} \cdot \mathrm{cm}^{-2}$. These results depicts that henna extract had a noticeable effect on the corrosion control of TMSM-PMMA coating on carbon steel substrate. Tafel test and impedance results confirm these descriptions.

\subsection{Microstructure of Hybrid Coating}

Figure 6 and Figure 7 show the scanning electron micrographs for hybrid coating of TMSM-PMMA thin layer with and without $3 \%$ henna extract before and after potentiodynamic polarization in HCL 0.1 M. By comparison of the SEM micrographs at the same magnifications for hybrid coating (with and without henna extract), it was observed that there were no traces of track on the surfaces of both specimens. After electrochemical tests, no corrosion was detected on the hybrid coatings including 3\% henna extract. However, after potentiodynamic polarization the surface of the specimen without henna extract $3 \%$ as an inhibitor was not smooth. The cracks and pits shown in Figure 6(b) indicated corrosion in the media without henna extract as an inhibitor. According to Figure 6(b), the regions surrounding corrosion were damaged. Therefore usage of inhibitor in the micro structure of the coatings can highly control the corrosion of the substrates. 
The data reported in Table 4 indicates that the strength of the bond between coating and substrate was increased in light of the inhibitor addition. Thus adhesion strength was enhanced by the presence of henna extract in the hybrid coating TMSM-PMMA. The chemical reaction between the components of

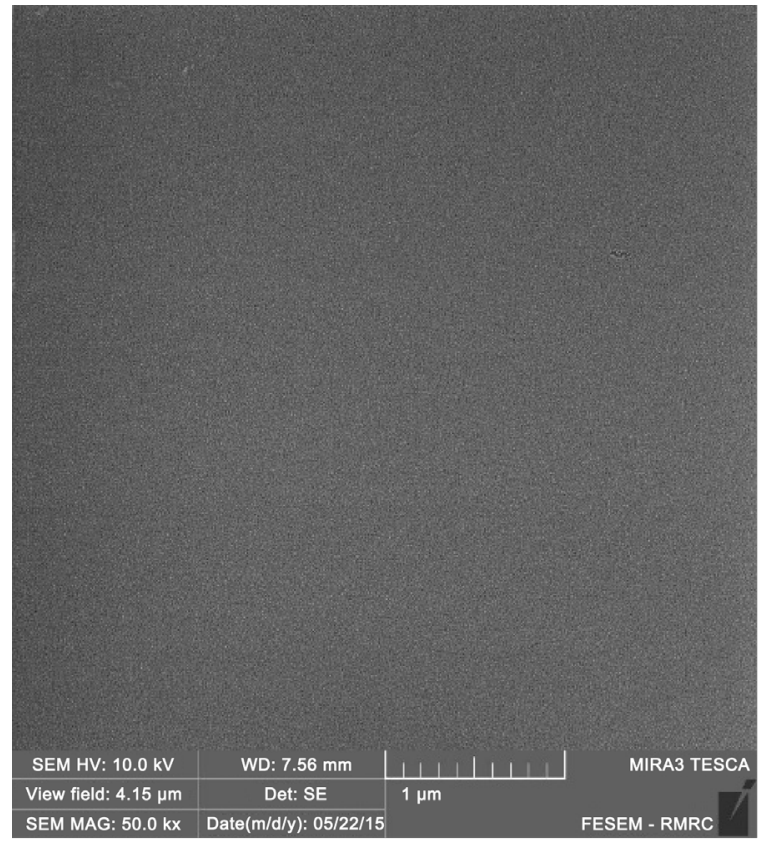

(a)

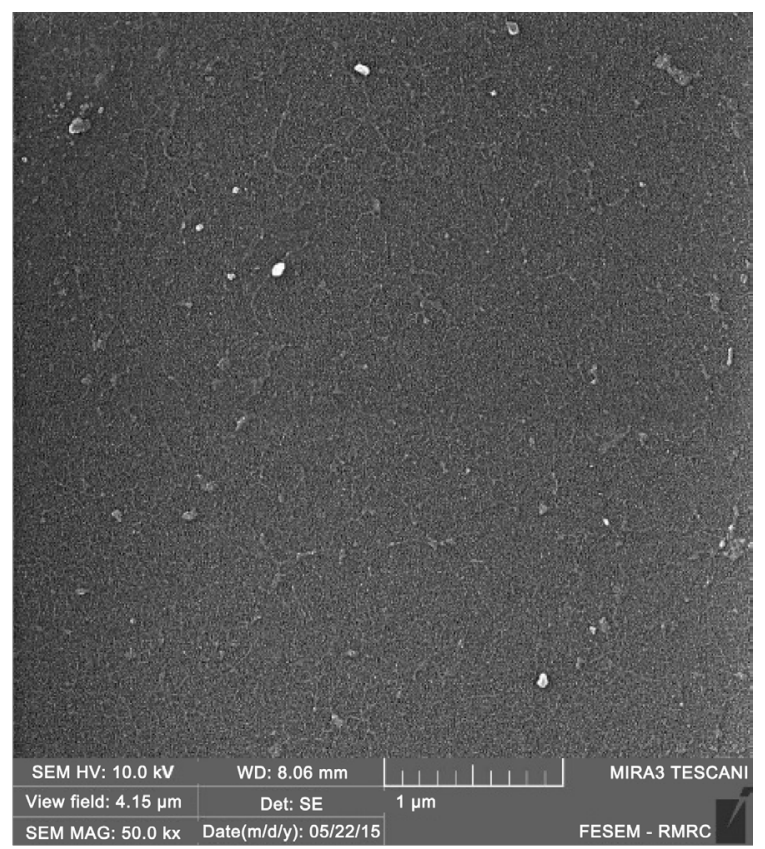

(b)

Figure 6. SEM images of hybrid coatings of TMSM-PMMA without henna extract before (a) and after (b) potentiodynamic tests in HCL $0.1 \mathrm{M}$ solution.

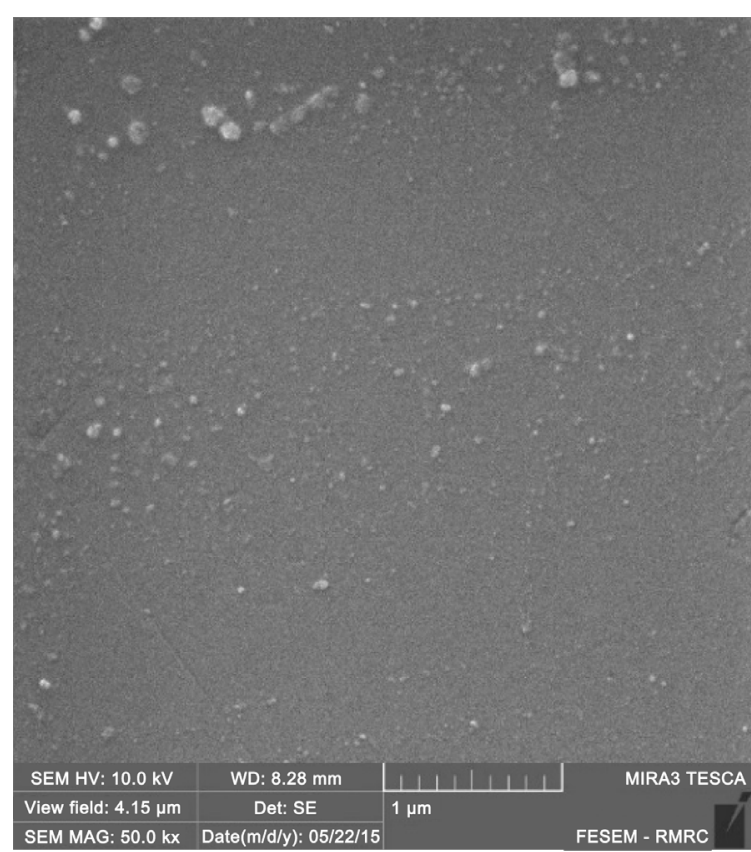

(a)

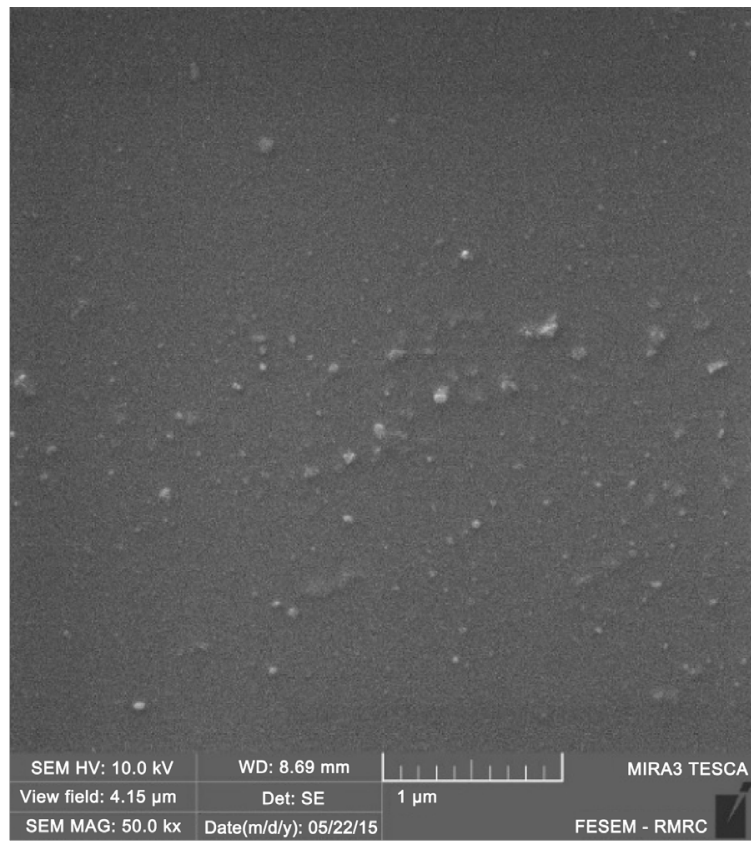

(b)

Figure 7. SEM images of hybrid coatings of TMSM-PMMA with $3 \%$ henna extract before (a) and after (b) potentiodynamic tests in HCL $0.1 \mathrm{M}$ solution. 
Table 4. Pull-off adhesion test in dry condition.

\begin{tabular}{cc}
\hline Specimen & Bond strength (MPa) \\
\hline No inhibitor & $5.3 \pm 0.1$ \\
$3 \%$ henna extract & $6.6 \pm 0.1$ \\
\hline
\end{tabular}

henna inhibitor and $\left(\mathrm{Fe}^{2+}\right)$ on carbon steel surface resulted in strengthening the bonds leading to the protection of the surface in aggressive environment.

\subsection{Inhibition Mechanism}

Henna leaves contain soluble matter Lawson (2-hydroxy-1, 4 naphthoquinone) resin and tannin, coumarins, gallic acid and Sterols shown in Figure 8 [39]. The amount of Lowsone in the henna leaves is $1.02 \%$ [40]. The coloring matter is quinine.

The inhibition performance of Tannins in alkaline media is higher in comparison with the acidic environments [40] [41]. The relatively higher amount of lawsone exits in the extract. Lawson molecule in the complex compound is a ligand and can constitute a chelate with a wide variety of metal cations. The inhibition mechanism is due to the reaction between substrate's cations and lawsone molecule. Aromatic compounds include rotating $\pi$-electron which is exposed to electron of the acid solution [42] [43] [44]. The hydroxyl group contains a pair of electrons in lawsone moleculein the case of the reaction between acid solution and lawsone molecule and this pair of electronsis rotating in the aromatic ring in acid chloridric solution leading to the scheme shown in Figure 9 [45] [46] [47]. When hydrogen atom migrates to the adjacent carbon with its electrons, the binary bond position changes in the cycle and this rearrangement results in lawsone isomer. This isomer combines with $\mathrm{Fe}^{2+}$ cations presenting in carbon steel, thus this formed combination leads to the inhibition of carbon steel in acid chloridric environment. On top of that, henna extract omits the deficiency in coating rising the inhibition efficiency [39] [48] [49] [50] [51].

\section{Conclusions}

The effect of henna extract as an inhibitor incorporated into sol-gel matrix TMSM-PMMA, was evaluated in HCL $0.1 \mathrm{M}$ on carbon steel specimens. The results are as followings:

1) By employing henna extract, there was no trace of cracks and pits on the surface of the specimens covered by hybridorganic-inorganic thin film.

2) Hybrid coating TMSM-PMMA offers a thin barrier protection and by the addition of henna, the inhibition efficiency reaches higher than $95 \%$.

3) SEM analyses for investigating the morphology of the sol-gel coatings with henna extract have shown that the uniformity of coating has not decreased by the addition of henna extract inhibitor.

4) Henna extract as an inhibitor could be categorized as a mixed-type kind which has a dominant effect in the cathodic part of the polarization curve. 
<smiles>O=C1C=C(O)C(=O)c2ccccc21</smiles>

(a)<smiles>O=C(O)c1cc(O)c(O)c(O)c1</smiles>

(b)

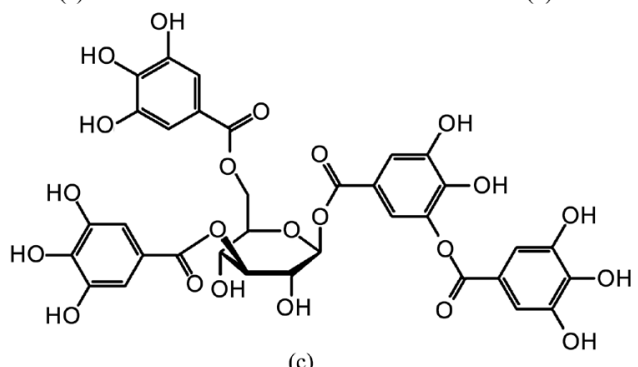

(c)

Figure 8. Molecular structure of a) Lawsone; b) Gallic acid and c) Tannic acid [40].<smiles>CC=CC=C1c2ccccc2C(=O)C1(O)CC</smiles>

Figure 9. Process of $\pi$-electron rotating on the lawsone molecule [45].

5) The TMSM-PMMA coating with $3 \%$ henna extract provided the maximum inhibition effect. This inhibitor could be a suitable and appropriate choice for the substitution of toxic inhibitors. Furthermore, it could be used as a desirable corrosion inhibitor.

6) The results achieved from SEM, potentiodynamic polarization and impedance measurement tests were all compatible.

\section{References}

[1] Chaudhari, H.G. and Vashi, R.V. (2016) The Study of Henna Leaves Extract as Green Corrosion Inhibitor for Mild Steel in Acetic Acid. Journal of Fundamental and Applied Sciences, 8, 280-296. https://doi.org/10.4314/jfas.v8i2.8

[2] Mojtaba, N.E., Pourriahi, M., Motalebi, A. and Zendehdel, M. (2013) Improvement of the Corrosion Performance of 304 L Stainless Steel by a Nanostructure Hybrid Coating/Henna Extract. Anti-Corrosion Methods and Materials, 61, 1-9. https://doi.org/10.1108/ACMM-12-2012-1229

[3] Toxicological Profile for Chromium, ATDSR/Tp-88/10 (1989) US Public Service, Washington, DC, Agency for Toxic Substances.

[4] Motalebi, A., Nasr-Esfahani, M., Ali, R. and Pourriahi, M. (2012) Improvement of Corrosion Performance of 316 L Stainless Steel via PVTMS/Henna Thin Film. Progress in Natural Science: Materials International, 22, 392-400. https://doi.org/10.1016/j.pnsc.2012.10.006 
[5] Fedel, M., Olivier, M., Poelman, M., Deflorian, F., Rossi, S. and Druart, M.E. (2009) Corrosion Protection Properties of Silane Pre-Treated Powder Coated Galvanized Steel. Progress in Organic Coatings, 66, 118-128. https://doi.org/10.1016/j.porgcoat.2009.06.011

[6] Bajat, J.B., Milosev, I., Jovanovic, Z., Jancic-Heinemann, R.M., Dimitrijevic, M. and Miskovic-Stankovic, V.B. (2010) Corrosion Protection of Aluminium Pretreated by Vinyltriethoxysilane in Sodium Chloride Solution. Corrosion Science, 52, 1060-1069. https://doi.org/10.1016/j.corsci.2009.11.035

[7] Cambon, J.B., Ansart, F., Bonino, J.P. and Turq, V. (2012) Effect of Cerium Concentration on Corrosion Resistance and Polymerization of Hybrid Sol-Gel Coating on Martensitic Stainless Steel. Progress in Organic Coatings, 75, 486-493.

https://doi.org/10.1016/j.porgcoat.2012.06.005

[8] Paula, P. and Heidi, M.F. (2001) Performance of Silane Treated Primed Hot-Dip Galvanised Steel. Anti-Corrosion Methods and Materials, 48, 7-17.

https://doi.org/10.1108/00035590110365273

[9] Hassannejad, H., Moghaddasi, M., Saebnoori, E. and Rabiei Baboukani, A. (2017) Microstructure, Deposition Mechanism and Corrosion Behavior of Nanostructured Cerium Oxide Conversion Coating Modified with Chitosan on AA2024 Aluminum Alloy. Journal of Alloys and Compounds, 725, 968-975.

https://doi.org/10.1016/j.jallcom.2017.07.253

[10] Raps, D., Hack, T., Wehr, J., Zheludkevich, M.L., Bastos, A.C., Ferreira, M.G.S. and Nuyken, O. (2009) Electrochemical Study of Inhibitor-Containing Organic-Inorganic Hybrid Coatings on AA2024. Corrosion Science, 51, 1012-1021. https://doi.org/10.1016/j.corsci.2009.02.018

[11] Yasakau, K.A., Zheludkevich, M.L., Karavai, O.V. and Ferreira, M.G.S. (2008) Influence of Inhibitor Addition on the Corrosion Protection Performance of Sol-Gel Coatings on AA2024. Progress in Organic Coatings, 63, 352-361. https://doi.org/10.1016/j.porgcoat.2007.12.002

[12] Cheng, Z., Foroughi, P. and Behrens, A. (2017) Synthesis of Nanocrystalline TaC Powders via Single-Step High Temperature Spray Pyrolysis from Solution Precursors. Ceramics International, 43, 3431-3434. https://doi.org/10.1016/j.ceramint.2016.11.177

[13] Al-Sehaibani, H. (2000) Evaluation of Extracts of Henna Leaves as Environmentally Friendly Corrosion Inhibitors for Metals. Materialwissenschaft und Werkstofftechnik, 31, 1060-1063. https://doi.org/10.1002/1521-4052(200012)31:12<1060::AID-MAWE1060>3.0.CO;2 $\underline{-\mathrm{K}}$

[14] Foroughi, P., Zhang, C., Agarwal, A. and Cheng, Z. (2017) Controlling Phase Separation of TaxHf1-xC Solid Solution Nanopowders during Carbothermal Reduction Synthesis. Journal of the American Ceramic Society, 100, 5056-5065. https://doi.org/10.1111/jace.15065

[15] Kunsta, S.R., Cardoso, H.R.P., Oliveira, C.T., Filho, C.I.S., Sarmento, V.H.V., Menezes, T.L., Muller, I.L. and Malfatti, C.F. (2013) Influence of Tetraethoxy Silane Addition in Siloxane-Poly (Methylmethacrylate) Hybrid Films Applied on Galvanized Steel. International Journal of Electrochemical Science, 8, 11984-12004.

[16] Schottner, G. (2001) Hybrid Sol-Gel-Derived Polymers: Applications of Multifunctional Materials. Chemistry of Materials, 13, 3422-3435. https://doi.org/10.1021/cm011060m

[17] Judeinstein, P. and Sanchez, C. (1996) Hybrid Organic-Inorganic Materials: A Land 
of Multidisciplinarity. Journal of Materials Chemistry, 6, 511-525. https://doi.org/10.1039/JM9960600511

[18] Shieh, Y.T., Liu, K.H. and Lin, T.L. (2004) Effect of Supercritical $\mathrm{CO}_{2}$ on Morphology of Compatible Crystalline/Amorphous PEO/PMMA Blends. The Journal of Supercritical Fluids, 28, 101-112. https://doi.org/10.1016/S0896-8446(03)00009-3

[19] Gu, S., Kondo, T. and Konno, M. (2004) Preparation of Silica-Polystyrene Core-Shell Particles up to Micron Sizes. Journal of Colloid and Interface Science, 272, 314-320. https://doi.org/10.1016/j.jcis.2004.01.056

[20] Sertchook, H. and Avnir, D. (2003) Submicron Silica/Polystyrene Composite Particles Prepared by a One-Step Sol-Gel Process. Chemistry of Materials, 15, 1690-1694. https://doi.org/10.1021/cm020980h

[21] Kim, W.S., Kim, K.S., Eo, Y.J., Yoon, K.B. and Bae, B.S. (2005) Synthesis of Fluorinated Hybrid Material for UV Embossing of a Large Core Optical Waveguide Structure. Journal of Materials Chemistry, 15, 465-469. https://doi.org/10.1039/b412419g

[22] Foroughi, P. and Cheng, Z. (2016) Understanding the Morphological Variation in the Formation of B4C via Carbothermal Reduction Reaction. Ceramics International, 42, 15189-15198. https://doi.org/10.1016/j.ceramint.2016.06.126

[23] Zhu, A., Shi, Z., Cai, A., Zhao, F. and Liao, T. (2008) Synthesis of Core-Shell PMMA-SiO ${ }_{2}$ Nanoparticles with Suspension-Dispersion-Polymerization in an Aqueous System and Its Effect on Mechanical Properties of PVC Composites. Polymer Testing, 27, 540-547. https://doi.org/10.1016/j.polymertesting.2007.11.005

[24] Delattre, L., Dupuy, C. and Babonneau, F. (1994) Characterization of the Hydrolysis and Polymerization Processes of Methacryloxypropyltrimethoxysilane. Journal of Sol-Gel Science and Technology, 2, 185-188. https://doi.org/10.1007/BF00486238

[25] Mansfeld, F. and Kendig, M.W. (1985) Electrochemical Impedance Spectroscopy of Protective Coatings. Materials and Corrosion, 36, 473-483.

https://doi.org/10.1002/maco.19850361102

[26] Rabiei Baboukani, A., Sharifi, E., Akhavan, S. and Saatchi, A. (2016) Co Complexes as a Corrosion Inhibitor for $316 \mathrm{~L}$ Stainless Steel in $\mathrm{H}_{2} \mathrm{SO}_{4}$ Solution. Journal of Materials Science and Chemical Engineering, 4, 28-35. https://doi.org/10.4236/msce.2016.49003

[27] López, D.A., Simison, D.A. and de Sánchez, S.R. (2003) The Influence of Steel Microstructure on $\mathrm{CO}_{2}$ Corrosion. EIS Studies on the Inhibition Efficiency of Benzimidazole. Electrochimica Acta, 48, 845-854. https://doi.org/10.1016/S0013-4686(02)00776-4

[28] Kurniawan, F. and Madurani, K.A. (2015)Electrochemical and Optical Microscopy Study of Red Pepper Seed Oil Corrosion Inhibition by Self-Assembled Monolayers (SAM) on 304 SS. Progress in Organic Coatings, 88, 256-262.

https://doi.org/10.1016/j.porgcoat.2015.07.010

[29] Quraishi, M.A., Singh, A., Singh, V.K., Yadav, D.K. and Singh, A.K. (2010) Green Approach to Corrosion Inhibition of Mild Steel in Hydrochloric Acid and Sulphuric Acid Solutions by the Extract of Murraya koenigii Leaves. Materials Chemistry and Physics, 122, 114-122. https://doi.org/10.1016/j.matchemphys.2010.02.066

[30] Hussin, M.H. and Kassim, M.J. (2011) The Corrosion Inhibition and Adsorption Behavior of Uncaria gambir Extract on Mild Steel in 1M HCl. Materials Chemistry and Physics, 125, 461-468. https://doi.org/10.1016/j.matchemphys.2010.10.032

[31] Rabiei Baboukani, A., Akhavan, S., Rezvani, M., Ebrahimi-Kahrizsangi, R. and Saatchi, A. (2016) Electrochemical Corrosion Behavior of Friction Stir Welded 
AA6061 in $\mathrm{NaCl}$ Solution. Proceedings of Iran International Aluminum Conference, Tehran, 11-12 May 2016.

[32] Mansfeld, F., Kendig, M.W. and Tsai, S. (1982) Evaluation of Corrosion Behavior of Coated Metals with AC Impedance Measurements. Corrosion, 38, 478-485. https://doi.org/10.5006/1.3577363

[33] Akhavan, S., Rabiei Baboukani, A., Saatchi, A., Ebrahimi-Kahrizsangi, R. and Shirmohammadi, S. (2014) Investigating the Anodizing Process of Aluminum Alloys in 0.3M Oxalic Acid and Its Metallurgical and Mechanical Behavior. Proceedings of Iran International Aluminum Conference, Tehran, 25-26 May 2014, 197-201.

[34] Lorenz, W.J. and Mansfeld, F. (1981) Determination of Corrosion Rates by Electrochemical DC and AC Methods. Corrosion Science, 21, 647-672.

https://doi.org/10.1016/0010-938X(81)90015-9

[35] Agrawal, R., Adelowo, E., Rabiei Baboukani, A., Villegas, M.F., Henriques, A. and Wang, C. (2017) Electrostatic Spray Deposition-Based Manganese Oxide FilmsFrom Pseudocapacitive Charge Storage Materials to Three-Dimensional Microelectrode Integrands. Nanomaterials, 7, 198. https://doi.org/10.3390/nano7080198

[36] SaebNoori, E., Navidinejad, A. and Rabiei Baboukani, A. (2016) Mechanism Study and Parameter Optimization of A356 Aluminum Alloy Electrochemical Polishing. Proceedings of Iran International Aluminum Conference, Tehran, 11-12 May 2016.

[37] Thomson, R.H. (1971) Naturally Occuring Quinones. Press London, New York.

[38] Rabiei Baboukani, A., Akhavan, S., Saatchi, A., Ebrahimi-Kahrizsangi, R. and Saebnoori, E. (2016) Mechanical Properties of AA2024 In the Presence of Al-Cu Intermetallic Surface Layer. Proceedings of Iran International Aluminum Conference, Tehran, 11-12 May 2016.

[39] El-Etre, A.Y., Abdallah, M. and El-Tantawy, Z.E. (2005) Corrosion Inhibition of Some Metals using Lawsonia Extract. Corrosion Science, 47, 385-395.

https://doi.org/10.1016/j.corsci.2004.06.006

[40] Ostovari, A., Hoseinieh, A.M., Peikari, A., Shadizadeh, S.R. and Hashemi, S.J. (2009) Corrosion Inhibition of Mild Steel in 1M HCl Solution by Henna Extract: A Comparative Study of the Inhibition by Henna and Its Constituents (Lawsone, Gallic Acid, $\alpha$-d-Glucose and Tannic Acid). Corrosion Science, 51, 1935-1949. https://doi.org/10.1016/j.corsci.2009.05.024

[41] Peiravi, M., Mote, S.R., Mohanty, M.K. and Liu, J. (2017) Bioelectrochemical Treatment of Acid Mine Drainage (AMD) from an Abandoned Coal Mine under Aerobic Condition. Journal of Hazardous Materials, 333, 329-338. https://doi.org/10.1016/j.jhazmat.2017.03.045

[42] Musa, A.Y., Kadhum, A.A.H., Mohamad, A.B. and Takriff, A.S. (2010) Experimental and Theoretical Study on the Inhibition Performance of Triazole Compounds for Mild Steel Corrosion. Corrosion Science, 52, 3331-3340. https://doi.org/10.1016/j.corsci.2010.06.002

[43] Peiravi, M., Ackah, L., Guru, R., Mohaty, M., Liu, K., Xu, B., Zhu, X. and Chen, L. (2017) Chemical Extraction of Rare Earth Elements from Coal Ash. Minerals \& Metallurgical Processing, 34, 170-177. https://doi.org/10.19150/mmp.7856

[44] Liu, J., Weinholtz, L., Zheng, L., Peiravi, M., Wu, Y. and Chen, D. (2017) Removal of PFOA in Groundwater by $\mathrm{Fe} 0$ and $\mathrm{MnO} 2$ Nanoparticles under Visible Light, Journal of Environmental Science and Health, Part A, 52, 1048-1054.

[45] CRC (2005) Handbook of Chemistry and Physics. Internet Version 2005, CRC Press, Boca Raton.

[46] Mafi, M., Martin, H. and Adjoudai, M. (2017) High Impulse Noice Intensity Re- 
moval in MRI Images. IEEE Signal Processing in Medicine and Biology Symposium, Philadelphia, December 1st.

[47] Mafi, M. (2012) Integration of Mobile Ad Hoc and WIMAX Networks with Approach of Admission Control and Hand off Combination Applied in Telemedicine Services. American Journal of Scientific Research, 83, 14-24.

[48] Khakpour, I., Soltani, R. and Sohi, M.H. (2015) Microstructure and High Temperature Oxidation Behaviour of Zr-Doped Aluminide Coatings Fabricated on Nickel-Based Super Alloy. Procedia Materials Science (Supplement C), 11, 515-521.

[49] Rezayan, A.H., Firoozi, N., Kheirjou, S., Tabatabaei Rezaei, S.J. and Reza Nahid, M. (2017) Synthesis and Characterization of Biodegradable Semi-Interpenetrating Polymer Networks Based on Star-Shaped Copolymers of $\varepsilon$-Caprolactone and Lactide. Iranian Journal of Pharmaceutical Research: IJPR, 16, 63-73.

[50] Rabiei Baboukani, A., Saatchi, A. and Ebrahimi-Kahrizsangi, R. (2012) Solid State Displacement Reaction Between $\mathrm{Ni}$ and $\mathrm{CuO}$ in $1000{ }^{\circ} \mathrm{C}$ as a High Temperature Composites. The $3 r d$ International Conference on Composites: Characterization, Fabrication and Application, 18-19 December 2012, Tehran.

[51] Awadallah, O. and Cheng, Z. (2017) Formation of Sel-Gel Based $\mathrm{Cu}_{2} \mathrm{ZnSnS}_{4}$ Thin Films using Ppm-Level Hydrogen Sulfide. Thin Solid Films, 625, 122-130.

https://doi.org/10.1016/j.tsf.2017.01.054 